\title{
Expression of Serum PTTG1 in Laryngeal Carcinoma and Its Correlation to Prognosis
}

\author{
Kunpeng $\mathrm{Ma}^{1}$ (i) $\cdot$ Xiuxia Sun ${ }^{1}$ (i) $\cdot$ Limin $\mathrm{Ma}^{2}$ (i) $\cdot$ Shenglin Zhang ${ }^{3}$ () \\ ${ }^{1}$ Department of Otorhinolaryngology, Affiliated Hospital of Weifang Medical University, Weifang; ${ }^{2}$ Department of Plastic Surgery, Plastic Surgery \\ Hospital of Weifang Medical University, Weifang; ${ }^{3}$ Department of Network Information Center, Weifang Medical University, Weifang, China
}

Objectives. The purpose of this study was to investigate serum pituitary tumor transforming gene (PTTG1) expression in laryngeal carcinoma and its relationship with the clinical pathological characteristics and prognosis.

Methods. Expression of serum PTTG1 was measured by enzyme-linked immunosorbent assay in 110 patients with laryngeal carcinoma and 60 patients with vocal cord polyps. Expression of the serum PTTG1 levels relationship with the clinicopathological characteristics and prognosis were analyzed.

Results. In laryngeal carcinoma patients' serum, the PTTG1 median concentration was $141.43 \mathrm{pg} / \mathrm{mL}$ (interquartile range [IQR], 111.387 to $160.837 \mathrm{pg} / \mathrm{mL}$ ), significantly higher than that of the vocal cord polyp group of $94.01 \mathrm{pg} / \mathrm{mL}$ (IQR, 81.26 to $108.59 \mathrm{pg} / \mathrm{mL})$, and the difference was statistically significant $(z=-6.715, P<0.001)$. PTTG1 expression with lymph node metastasis, clinical stage, and patients with laryngeal carcinoma was significantly correlated with the tumor differentiation degree $(P<0.05)$. The total survival rate of the PTTG1 high expression group was significantly lower than the low expression group, and the difference of total survival time of the two groups was statistically significant $(P<0.001)$.

Conclusion. The PTTG1 expression level can be used as an index for evaluating prognosis of laryngeal cancer. High PTTG1 expression is one of the factors of poor prognosis of laryngeal carcinoma patients.

Keywords. Laryngeal Cancer; Serum; Transforming Genes; Prognosis

\section{INTRODUCTION}

Laryngeal cancer is a primary malignant tumor in the laryngeal mucosa, and its incidence rate is the second highest of head and neck malignant tumors. Its pathogenesis is still not fully understood [1]. The main pathological type of laryngeal cancer is squamous cell carcinoma, accounting for $95 \%-98 \%$ of all laryngeal cancers [2]. Although the treatment of laryngeal cancer has improved, the 5 -year survival rate of laryngeal cancer patients has not significantly improved [3,4]. Invasion and metas-

\footnotetext{
- Received March 18, 2019

Revised June 16, 2019

Accepted June 26, 2019

- Corresponding author: Kunpeng Ma

Department of Otorhinolaryngology, Affiliated Hospital of Weifang Medical University, No. 2428 Yuhe Rd Kuiwen District, Weifang, Shandong Province 261031, China

Tel: +86-0536-3081375, Fax: +86-0536-3081177

E-mail: maxiaofei918@126.com
}

tasis are important characteristics of malignant tumors and also the key factors to determine the prognosis of patients [5].Tumor growth and infiltration is a complex process regulated by oncogenes and is the main cause of poor prognosis in laryngeal cancer patients [6]. The pituitary tumor transforming gene (PTTG1) is the first proto-oncogene detected from rat pituitary tumor cells [7]. PTTG1 was found to be related to the degree of tumor differentiation and invasion and metastasis, and is an important factor leading to a poor prognosis of patients [8]. Many studies showed that PTTG1 is highly expressed only in normal tissues such as testis, thymus, embryos, and liver with high cell proliferation activity, while it is only weakly expressed or undetectable in other normal parts, but it is highly expressed in all tumor cells studied $[9,10]$. The purpose of this study was to analyze the relationship between the PTTG1 level and prognosis of laryngeal cancer by detecting the PTTG1 level in the serum of laryngeal cancer patients, and to provide some theoretical basis for diagnosis and prognosis of laryngeal cancer patients.

Copyright $\odot 2020$ by Korean Society of Otorhinolaryngology-Head and Neck Surgery

This is an open-access article distributed under the terms of the Creative Commons Attribution Non-Commercial License (https://creativecommons.org/licenses/by-nc/4.0)

which permits unrestricted non-commercial use, distribution, and reproduction in any medium, provided the original work is properly cited. 


\section{MATERIALS AND METHODS}

\section{Materials}

Specimens were collected from 110 patients with laryngeal squamous cell carcinoma treated in the ENT Department of Affiliated Hospital of Weifang Medical University from 2013 to 2017, including 99 male patients, 11 female patients, aged 39 to 80 years, with an average of 62.3 years old, 18 highly differentiated patients, 33 moderately differentiated patients, 59 poorly differentiated patients, 67 with lymph node metastasis, and 43 without metastasis. According to the staging system of malignant tumors (Union for International Cancer Control 2010) [11], there were 45 cases of stage I-II, 65 cases of stage III-IV, 35 cases of the supraglottic type, 67 cases of the glottic type, and eight cases of the subglottic type. There was no history of radiotherapy or chemotherapy before the operation. Another 60 cases of vocal cord polyp tissues were taken as the control group, all confirmed by hematoxylin and eosin stain staining. The survival time was calculated from the operation date to the last follow-up date to the death date of the patient due to tumor recurrence and metastasis. The follow-up period was 7 to 60 months, with an average of 39.5 months. All the specimens were obtained with the informed consent of the patients. The design of this study complied with the ethical standards set forth in the 1975 Helsinki Declaration and approved by Institutional Review Board of the hospital (IRB No. 2012-247). Blood samples collected from all laryngeal cancer patients were $5 \mathrm{~mL}$ of whole blood taken from the abdominal elbow vein 2-3 days before operation. They were placed in a vacuum blood collection vessel without anticoagulant, stored in a refrigerator at $4^{\circ} \mathrm{C}$, centrifuged at $3,000 \mathrm{r} / \mathrm{min}$ within 72 hours. The supernatant was taken after 10-15 minutes, placed in a centrifuge tube, and stored in a refrigerator at $-80^{\circ} \mathrm{C}$ for later use.

\section{Main reagents and sources}

The serum PTTG1 concentration was detected by double antibody sandwich enzyme-linked immunosorbent assay (ELISA)

\section{H I G H L I G G H T S}

- Pituitary tumor transforming gene (PTTG1) expression with lymph node metastasis, clinical stage, and patients with laryngeal carcinoma was significantly correlated with the tumor differentiation degree $(P<0.05)$.

- The total survival rate of the PTTG1 high expression group was significantly lower than the low expression group, and the difference of total survival time of the two groups was statistically significant $(P<0.001)$.

- The PTTG1 expression level can be used as an index for evaluating prognosis of laryngeal cancer.

- High PTTG1 expression is one of the factors of poor prognosis of laryngeal carcinoma patients. kit, purchased from Shanghai Linc-Bio Science (Shanghai, China).

\section{Experimental method}

Double antibody sandwich ELISA: a PTTG1 ELISA kit was used to determine the PTTG1 concentration in the serum. The main steps are as follows: preprepared standards and samples were added into microplates and well shaken at $37^{\circ} \mathrm{C}$ for 30 minutes. After the microplate was rinsed, $50 \mu \mathrm{L}$ of secondary antibody was added and allowed to stand at room temperature for 30 minutes. After washing, the substrate was added, and after 30 minutes in the dark, the termination liquid was added. The absorbance $A$ value was detected at $450 \mathrm{~nm}$ by a microplate reader, and the PTTG1 concentration was calculated according to the standard curve. All specimens were tested three times and then a weighted average was determined.

\section{Statistical methods}

SPSS ver. 17.0 (SPSS Inc., Chicago, IL, USA) was used for statistical analysis. The data of normal distribution are expressed by $\chi \pm \mathrm{s}$, and the analysis of the average number of two samples was determined by the $t$-test. The data of nonnormal distribution was expressed by the median (interquartile range [IQR]: 25-75 percentiles), and the data comparison between different groups was determined by the Mann-Whitney rank-sum test. The survival analysis of patients was examined by the KaplanMeier log-rank method. The Cox risk regression model was used to analyze single factors and multiple factors. A $P<0.05$ was statistically significant.

\section{RESULTS}

The median concentration of serum PTTG1 in laryngeal cancer patients was $141.43 \mathrm{pg} / \mathrm{mL}$ (IQR, 111.387 to $160.837 \mathrm{pg} / \mathrm{mL}$ ), which was significantly higher than the $94.01 \mathrm{pg} / \mathrm{mL}$ (IQR,

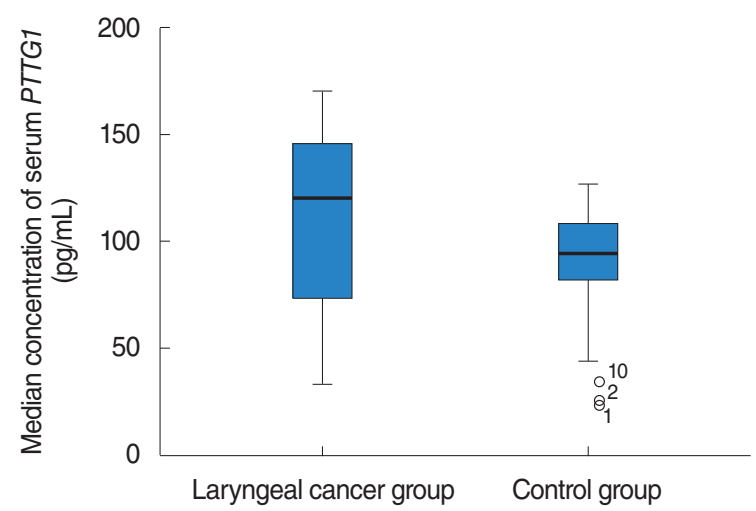

Fig. 1. The serum level of PTTG1 in the laryngeal cancer group and the control group. The median concentration of serum PTTG1 in laryngeal cancer patients was significantly higher than that in the vocal cord polyp group. There was a significant difference $(P<0.001)$. 


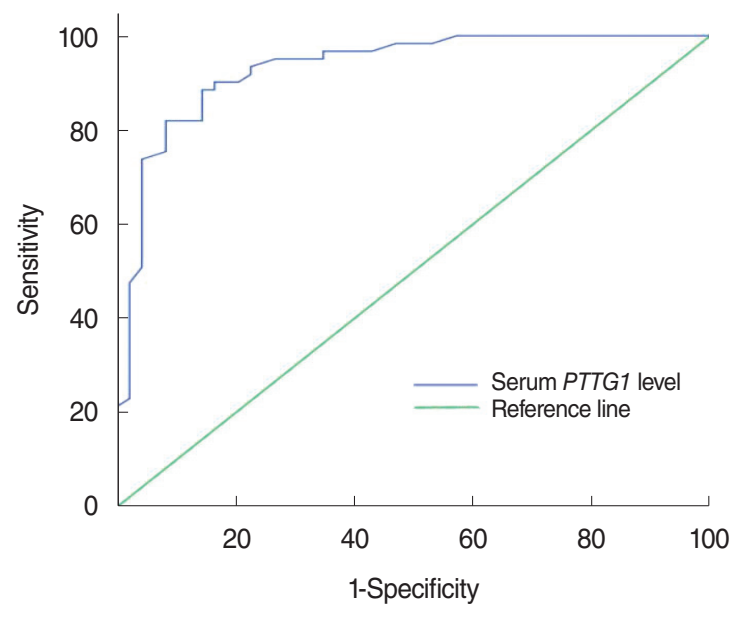

Fig. 2. The receiver operating characteristic curve of PTTG1 expression in the serum of laryngeal cancer patients. PTTG1 has high sensitivity and specificity in the serum of laryngeal cancer patients. The sensitivity was $88.5 \%$, the specificity was $85.7 \%$, and the area under the curve was 0.933 .

Table 1. Relationship between PTTG1 expression and clinicopathological characteristics

\begin{tabular}{lrcrc}
\hline Characteristics & Case & PTTG1 & Z value & $P$-value \\
\hline Sex & & & -0.670 & 1.000 \\
$\quad$ Male & 99 & $162.64(136.10-256.68)$ & & \\
$\quad$ Female & 11 & $177.69(134.25-247.41)$ & & \\
Age $(y r)$ & & & -0.153 & 0.642 \\
$\quad \geq 55$ & 76 & $159.72(126.28-248.12)$ & & \\
$\quad<55$ & 34 & $170.87(130.21-267.43)$ & & \\
Lymph node metastasis & & & -3.763 & 0.001 \\
$\quad$ Present & 67 & $180.17(154.67-289.38)$ & & \\
$\quad$ Absent & 43 & $147.29(127.23-242.85)$ & & \\
TNM tumor stage & & & -2.237 & 0.001 \\
$\quad$ I+II & 45 & $162.36(122.61-213.74)$ & & \\
$\quad$ III+IV & 65 & $283.53(158.36-290.41)$ & & \\
Tumor differentiation & & & -4.125 & 0.001 \\
$\quad$ Well moderate & 51 & $156.12(124.17-211.81)$ & & \\
$\quad$ Poor & 59 & $227.59(157.73-318.39)$ & & \\
Tumor location & & & -0.528 & 0.948 \\
$\quad$ Supraglottic+glottic & 102 & $165.37(128.68-237.39)$ & & \\
\hline Subglottic & 8 & $172.85(147.31-265.36)$ & & \\
\hline
\end{tabular}

Values are presented as median (interquartile range).

81.26 to $108.59 \mathrm{pg} / \mathrm{mL}$ ) in the vocal cord polyps group, with a statistically significant difference $(z=-6.715, P<0.001)$ (Fig. 1). The sensitivity of PTTG1 expression in the serum of laryngeal cancer patients and the best discriminant point of PTTG1 expression in the serum of specific laryngeal cancer patients was $0.742 \mathrm{IU} / \mathrm{mL}$, the sensitivity was $88.5 \%$, the specificity was $85.7 \%$, and the area under the curve was 0.933 (Fig. 2).

The relationship between PTTG1 expression and clinicopathological features: PTTG1 expression had a significant correlation with lymph node metastasis, clinical stage, and tumor differenti-

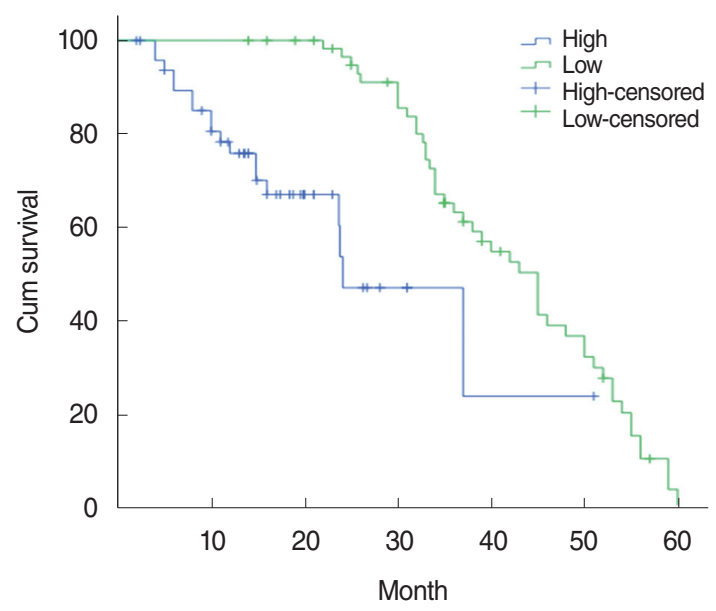

Fig. 3. The survival curve of PTTG1 patients with high and low expression. Kaplan-Meier analysis of the total survival time of the PTTG1 high-expression group and the low-expression group showed that the total survival time of the PTTG1 high-expression group was significantly lower than that of the low-expression group, and the difference in total survival time between the two groups was significant $(P<0.001)$.

ation in laryngeal cancer patients $(P<0.05)$, but had no correlation with age, sex, and the tumor growth site $(P>0.05)$ (Table 1$)$. The relationship between PTTG1 expression and the survival prognosis of patients: using the median serum PTTG1 concentration of $141.43 \mathrm{pg} / \mathrm{mL}$ as the demarcation point was determined. The 110 laryngeal cancer patients were divided into two groups: PTTG1 $>141.43 \mathrm{pg} / \mathrm{mL}$ was the high expression group with 49 cases and PTTG1 $\leq 141.43 \mathrm{pg} / \mathrm{mL}$ was the low expression groups with 61 cases. Kaplan-Meier analysis of the total survival time of the PTTG1 high expression group and the low expression group showed that the total survival rate of the PTTG1 high expression group was significantly lower than that of the low expression group, and the difference in total survival time between the two groups was statistically significant $(P<$ 0.001) (Fig. 3).

\section{DISCUSSION}

Laryngeal cancer is a malignant tumor with a high incidence rate. Its formation and development is a complex process of multiple genes acting together. Apoptosis and abnormal cell proliferation caused by proto-oncogene regulation play an important role in the invasion and metastasis of laryngeal cancer. The PTTG1 is a mammalian protein originally isolated from mouse pituitary tumor cells and identified as a member of the Securin protein family $[7,12]$. PTTG1 is a multifunctional protein that plays an important role in cell transformation, DNA repair, and transcription regulation [7,13-16]. Pei and Melmed [7] found that subcutaneous injection of PTTG-transfected NIH 3T3 cells into nude mice which quickly induced malignant tumors [17], 
are a kind of carcinogenic gene with strong effects [18]. Highly expressed PTTG1 plays an important role in accelerating the division and differentiation of tumor cells and the formation of tumor cells, studies by Pezzani et al. [19] have also confirmed this view.

In this study, the serum PTTG1 concentration was detected by double antibody sandwich ELISA in order to analyze its relationship with clinicopathological characteristics and prognosis of laryngeal squamous cell carcinoma. Experimental results showed that the serum PTTG1 median concentration in patients with laryngeal squamous cell carcinoma was significantly higher than that in the control group $(P<0.001)$, suggesting that the peripheral serum PTTG1 was derived from laryngeal cancer tissue. The increase of PTTG1 expression in laryngeal cancer cells led to a significant increase in the serum PTTG1 level in laryngeal squamous cell carcinoma patients compared with the control group, suggesting that the PTTG1 level is related to the occurrence and development of tumors. This indicated that PTTG1 can lead to laryngeal cancer by being a protooncogene, and the increase in PTTG1 concentration can indicate the growth and infiltration of the tumor and can be used as an early auxiliary diagnostic index for laryngeal cancer.

In this study, there was a significant correlation between PTTG1 expression and lymph node metastasis, clinical staging, and tumor differentiation in patients with laryngeal carcinoma $(P<0.05)$, and serum PTTG1 levels in patients with lymph node metastasis were significantly higher than in patients without lymph node metastasis $(P<0.05)$. The serum level of stage III-IV patients was significantly higher than that of stage I-II patients $(P<0.05)$, and that of low-differentiated patients was significantly higher than that of high-differentiated patients $(P<0.05)$, which indicated that PTTG1 expression was closely related to tumor lymph node metastasis, staging, and malignant degree. This suggested that the expression level of PTTG1 was related to the occurrence and development of malignant tumors. From this analysis it was found that in the course of tumor development, tumor cell necrosis or tumor cells in the infiltration and metastasis secondarily released more PTTG1, resulting in a higher concentration in the serum. The expression level of PTTG1 in the serum can indirectly reflect the stage and differentiation degree of tumors, PTTG1 expression results are consistent with lymph node metastasis, clinical stage and tumor differentiation degree, which can complement and verify each other in the diagnosis and stage of laryngeal cancer, suggesting that PTTG1 can promote the metastasis of laryngeal carcinoma and play an important role in the occurrence, development, and transfer of laryngeal carcinoma. PTTG1 has high sensitivity and specificity in the serum of patients with laryngeal cancer, and may become a new serological marker. Multi-factor analysis of the Cox regression model showed that the concentration of PTTG1 in the serum is an independent risk factor affecting the survival prognosis of laryngeal carcinoma patients.
The cumulative survival rate of 3 years and 5 years after operation in the PTTG1 low expression group was $87.53 \%$, the cumulative survival rate of 3 years and 5 years after operation was $71.24 \%$, whereas in the PTTG1 high expression group it was $39.97 \%$ and $4.61 \%$, respectively, and the total survival rate of the PTTG1 high expression group in laryngeal carcinoma was significantly lower than that of the low expression group. There was a significant difference in total survival time between the two groups $(P<0.001)$. The total survival rate of PTTG1 was negatively correlated, the higher the expression of PTTG1, the shorter the survival period of patients. The significant difference between low expression and high expression indicated that patients with high expression were more prone to tumor recurrence and metastasis, showing that PTTG1 was involved in the invasion and metastasis of laryngeal cancer. This suggested that PTTG1 is one of the factors of a poor prognosis of laryngeal carcinoma. It can be used as an indicator to assess the prognosis of laryngeal cancer.

The results of this study showed that PTTG1 may be a potential serum marker for laryngeal cancer, and the prognosis of laryngeal cancer can be predicted by detecting PTTG1 expression, but the sample size and long-term follow-up should be further expanded to clarify its early diagnostic value for laryngeal cancer and provide a new target for the diagnosis and gene therapy of laryngeal cancer.

\section{CONFLICT OF INTEREST}

No potential conflict of interest relevant to this article was reported.

\section{ORCID}

Kunpeng Ma https://orcid.org/0000-0001-6833-8583

Xiuxia Sun https://orcid.org/0000-0002-3516-6989

Limin Ma https://orcid.org/0000-0001-6712-8218

Shenglin Zhang https://orcid.org/0000-0002-2479-7822

\section{AUTHOR CONTRIBUTIONS}

Conceptualization: KM. Data curation: KM, XS. Formal analysis: LM. Methodology: SZ. Project administration: KM. Visualization: SZ.Writing - original draft: KM.Writing - review \& editing: KM.

\section{REFERENCES}

1. Siegel R, Naishadham D, Jemal A. Cancer statistics, 2012. CA Cancer J Clin. 2012 Jan-Feb;62(1):10-29. 
2. Rudolph E, Dyckhoff G, Becher H, Dietz A, Ramroth H. Effects of tumour stage, comorbidity and therapy on survival of laryngeal cancer patients: a systematic review and a meta-analysis. Eur Arch Otorhinolaryngol. $2011 \mathrm{Feb}$;268(2):165-79.

3. Siegel R, Ma J, Zou Z, Jemal A. Cancer statistics, 2014. CA Cancer J Clin. 2014 Jan-Feb;64(1):9-29.

4. Hoffman HT, Porter K, Karnell LH, Cooper JS, Weber RS, Langer CJ, et al. Laryngeal cancer in the United States: changes in demographics, patterns of care, and survival. Laryngoscope. 2006 Sep;116(9 Pt 2 Suppl 111):1-13.

5. Hanahan D, Weinberg RA. The hallmarks of cancer. Cell. 2000 Jan; 100(1):57-70.

6. Smee RI, De-loyde KJ, Broadley K, Williams JR. Prognostic factors for supraglottic laryngeal carcinoma: importance of the unfit patient. Head Neck. 2013 Jul;35(7):949-58.

7. Pei L, Melmed S. Isolation and characterization of a pituitary tumortransforming gene (PTTG). Mol Endocrinol. 1997 Apr;11(4):433-41.

8. Li H, Yin C, Zhang B, Sun Y, Shi L, Liu N, et al. PTTG1 promotes migration and invasion of human non-small cell lung cancer cells and is modulated by miR-186. Carcinogenesis. 2013 Sep;34(9):2145-55.

9. Wierinckx A, Auger C, Devauchelle P, Reynaud A, Chevallier P, Jan $\mathrm{M}$, et al. A diagnostic marker set for invasion, proliferation, and aggressiveness of prolactin pituitary tumors. Endocr Relat Cancer. 2007 Sep;14(3):887-900.

10. Xiao JQ, Liu XH, Hou B, Yao Y, Deng K, Feng M, et al. Correlations of pituitary tumor transforming gene expression with human pituitary adenomas: a meta-analysis. PLoS One. 2014 Mar;9(3):e90396.

11. Edge SB, Compton CC. The American Joint Committee on Cancer: the 7th edition of the AJCC cancer staging manual and the future of
TNM.Ann Surg Oncol. 2010 Jun;17(6):1471-4.

12. Zou H, McGarry TJ, Bernal T, Kirschner MW. Identification of a vertebrate sister-chromatid separation inhibitor involved in transformation and tumorigenesis. Science. 1999 Jul;285(5426):418-22.

13. Ramos-Morales F, Dominguez A, Romero F, Luna R, Multon MC, Pintor-Toro JA, et al. Cell cycle regulated expression and phosphorylation of hpttg proto-oncogene product. Oncogene. 2000 Jan;19(3): 403-9.

14. Tong Y,Tan Y, Zhou C, Melmed S. Pituitary tumor transforming gene interacts with $\mathrm{Sp} 1$ to modulate $\mathrm{G} 1 / \mathrm{S}$ cell phase transition. Oncogene. 2007 Aug;26(38):5596-605.

15. Bradshaw C, Kakar SS. Pituitary tumor transforming gene: an important gene in normal cellular functions and tumorigenesis. Histol Histopathol. 2007 Feb;22(2):219-26.

16. Bernal JA, Roche M, Mendez-Vidal C, Espina A,Tortolero M, PintorToro JA. Proliferative potential after DNA damage and non-homologous end joining are affected by loss of securin. Cell Death Differ. 2008 Jan;15(1):202-12.

17. McCabe CJ, Gittoes NJ. PTTG: a new pituitary tumour transforming gene. J Endocrinol. 1999 Aug;162(2):163-6.

18. Zhang X, Horwitz GA, PrezantTR,Valentini A, Nakashima M, Bronstein MD, et al. Structure, expression, and function of human pituitary tumor-transforming gene (PTTG). Mol Endocrinol. 1999 Jan; 13(1):156-66.

19. Pezzani R, Bertazza L, Cavedon E, Censi S, Manso J, WatutantrigeFernando S, et al. Novel prognostic factors associated with cell cycle control in sporadic medullary thyroid cancer patients. Int J Endocrinol. 2019 Feb;2019:9421079. 